Research Article

\title{
Decision-Making Behavior of Fertilizer Application of Grain Growers in Heilongjiang Province from the Perspective of Risk Preference and Risk Perception
}

\author{
Xin Li and Jie Shang \\ College of Economy and Management, Northeast Forestry University, Harbin 150040, China \\ Correspondence should be addressed to Jie Shang; hello_o_o@nefu.edu.cn
}

Received 7 December 2020; Revised 21 January 2021; Accepted 8 February 2021; Published 20 February 2021

Academic Editor: Sang-Bing Tsai

Copyright (c) 2021 Xin Li and Jie Shang. This is an open access article distributed under the Creative Commons Attribution License, which permits unrestricted use, distribution, and reproduction in any medium, provided the original work is properly cited.

\begin{abstract}
Heilongjiang Province, as a major grain-planting province in China, under the condition of limited production level and cognitive level, the food and agriculture industry often adopts the "high input-high output" production model to achieve grain yield and increase production. As one of the important material input elements in agricultural production, chemical fertilizer plays an irreplaceable role in increasing crop output and farmers' income. The reduced application of chemical fertilizer can improve the soil and water source, improve the production environment from the internal agricultural production, and ensure the quality and safety of agricultural products from the source, which is beneficial to the sustainable development of agriculture in China. In this paper, Probit model is used to analyze the risk preference and risk perception of grain farmers in Heilongjiang Province. The results showed that high degree of risk preference had a negative effect on decision behavior of fertilizer application, while high natural risk perception had a positive effect on fertilizer application behavior of grain farmers. At the same time, the results showed that the cultivated land area owned by farmers, the total income of agricultural production, the training of fertilizer technology, and the cognition of the impact of fertilizer on the environment all had significant effects on the chemical fertilizer application behavior of grain farmers. Finally, according to the results of this study, some feasible suggestions are put forward.
\end{abstract}

\section{Introduction and Literature Review}

Agriculture is a typical risk industry. In the process of agricultural production and agricultural products management, farmers will face uncertainty from nature, market, agricultural system, and so on [1]. As one of the main material input factors to provide nutrients and efficacy of crops, chemical fertilizers play an irreplaceable role in improving the yield and quality of agricultural products [2]. According to the experience of agricultural development in the world, the application of chemical fertilizer has played an important role in meeting the demand for agricultural products and achieving agricultural modernization and agricultural sustainable development $[3,4]$. According to a large number of research data, under the dual constraints of natural risk and market risk, farmers tend to increase the input of chemical fertilizer and pesticides to ensure the quality and yield of agricultural products. Excessive application of chemical fertilizer is common among Chinese farmers, and excessive chemical input has caused serious environmental problems, which has become the bottleneck constraint of sustainable development of agriculture in China [5-7].

In the aspect of farmers' fertilization behavior, some scholars mainly studied it from the perspective of family characteristics and farmers' characteristics. They find that the number of household labor force, the age of household head, education level, gender of household head, nonagricultural income, farmers' concern about the environment, and so on have an impact on farmers' fertilization behavior [8-10]. When agriculture faces the risk of natural disasters, the risk decision-making behavior of farmers under uncertainty is affected by its risk characteristics. The risk decision-making behavior of farmers is a function of risk preference and risk 
perception [11]. Roumasset and Scott put forward farmers as "risk averse"; farmers' risk preference and risk perception will directly affect farmers' fertilization behavior [12, 13]. Farmers' risk decision-making behavior is affected by the degree of risk preference, which shows that farmers with higher risk aversion are more likely to take risk resistance behavior to reduce losses [14]. Huanguang et al. explaining farmers' overfertilization behavior from the perspective of farmers' risk aversion believe that the risk characteristics of farmers are an important factor affecting the amount of fertilizer used by farmers. Farmers with high degree of risk aversion are more inclined to use fertilizer to reduce losses and reduce production uncertainty [15]. Research by Roydatul Zikria and Arie Damayanti showed that agricultural extension can significantly reduce the amount of chemical fertilizers used in Indonesian rice cultivation; the risk preference of farmers has a significant negative impact on fertilizer overuse. Lusk and Coble revealed that perception plays an important role in farmers' risk decision-making behavior research, and risk perception is even more important than risk preference [16]. Patil and Veettil indicated that, in developing countries, covariate production risk is one of the main characteristics of the agricultural sector, and farmers' risk attitudes play a crucial role in designing and determining risk mitigation mechanisms [17]. Camacho-Cuena and Requate designed experiments to examine the effect of collective penalty, immediate penalty, and tax subsidy schemes on agricultural pollution abatement for farmers with different risk preferences. The results show that if farmers are risk averse, tax subsidies can effectively alleviate the problem of excessive emission reduction [18]. Qiu et al. obtained farmers' risk preference index using experimental economics and found that risk preference has different influence on farmers' adoption of conservation tillage technology under different risk perception [19-21]. To sum up, fertilization behavior as one of the important behaviors to ensure farmers' production benefits is affected by their risk preference and risk perception.

Heilongjiang Province is an important agricultural production area in China. It has abundant agricultural production resources. However, its agricultural infrastructure construction is not perfect, and its ability to resist natural disasters is relatively weak. Therefore, the agricultural production high risk characteristic is obvious. Selecting grain farmers in Heilongjiang Province as the research object of this paper has a certain representative role and practical significance in promoting China's agricultural development. Through reading the literature, it is found that there are few studies on the influence of risk preference and risk perception on farmers' fertilizer behavior decision-making. Therefore, this paper selects Heilongjiang Province as a sample area, takes risk preference and risk perception as the research entry point, studies farmers' chemical fertilizer application decision-making behavior, and simulates the possible influence of farmers' risk preference on fertilizer application behavior decision-making of grain farmers. From the point of view of risk preference and risk perception, this paper puts forward some ideas and countermeasures to optimize the fertilizer behavior of grain farmers, guide grain farmers to fertilize scientifically and reasonably, and achieve the purpose of reducing ecological environment pollution and realizing sustainable development of agriculture.

\section{Theoretical Logic and Model Setting}

2.1. Theoretical Logic. The cognition and preference of grain farmers to risks in production have the general attribute of farmers' behavior. Farmers' decision-making on chemical fertilizer application behavior will directly affect farmers' own interests and the quality and safety of agricultural products, but under the influence of their subjective judgment, the decisions of different farmers must be different. Based on Expected Utility Theory and Risk-Return Theory, this paper draws on the analysis of Lusk and Coble to establish a theoretical model of the relationship among risk preference, risk perception, and fertilization behavior of grain farmers [16]. This paper assumes that grain farmers are risk averse, and grain farmers believe that appropriate increase in fertilizer application can protect their own revenue function. In order to study the effect of risk perception and risk preference on chemical fertilizer application decision-making behavior of grain farmers, the utility function of grain farmers is $U(W)$, where $W$ is wealth. The expected value of incremental application of chemical fertilizer is expressed by random variable $Z$. $C$ is defined as the risk premium of incremental fertilization behavior of grain farmers; that is, the utility of incremental fertilizer and loss of $C$ amount of uncertainty currency have no difference. Thus, the following equation holds:

$$
\begin{aligned}
E[U(W+Z)] & =U[W+E(Z)-C], \\
E(Z) & =a, \\
\operatorname{var}(Z) & =\sigma^{2} .
\end{aligned}
$$

In formulas (2) and (3), $a$ is positive, which means that the average effect of increasing fertilizer application on grain farmers' income is positive. $\sigma^{2}$ is the variance of random variable $Z$, which represents farmer's perception of agricultural risk. The higher the perceived risk of grain farmers, the greater the $\sigma^{2}$.

Suppose the utility function $U(\cdot)$ is a continuous second derivative function. The utility function $U(W+E(Z)-C)$ is a first-order Taylor expansion at $[W+E(Z)]$. The results are as follows:

$$
U[W+E(Z)-C] \approx U[W+E(Z)]-\frac{\partial U}{\partial W} \cdot C .
$$

The utility function $U(W+E(Z))$ is used to carry out the first-order Taylor expansion and the second-order Taylor expansion at $[W+E(Z)]$. The results are as follows:

$$
\begin{aligned}
U(W+Z) \approx & U[W+E(Z)]+\frac{\partial U}{\partial W} \cdot[Y-E(Z)] \\
& +0.5 \cdot \frac{\partial^{2} U}{\partial W^{2}} \cdot[Y-E(Z)]^{2}
\end{aligned}
$$


According to equation (5), and $E[Z-E(Z)]=0$, the expected result of utility function $U(W+Z)$ is as follows:

$$
E[U(W+Z)] \approx E\{U[W+E(Z)]\}+0.5 \cdot \frac{\partial^{2} U}{\partial W^{2}} \cdot \sigma^{2} .
$$

Let $U^{\prime}=(\partial U / \partial W), \quad U^{\prime \prime}=\left(\partial^{2} U / \partial W^{2}\right)$, which can be solved by equations (4) and (6):

$$
C \approx-\frac{1}{2}\left(\frac{U^{\prime \prime}}{U^{\prime}}\right) \sigma^{2}=\frac{1}{2} \cdot C(W) \cdot \sigma^{2},
$$

where $C(W)$ in equation (7) is Arrow-Pratt absolute risk aversion coefficient. The increase of $C(W)$ means that the degree of risk aversion increases.

2.2. Model Setting. In order to investigate the influence of risk preference and risk perception on fertilizer application behavior of grain farmers in Heilongjiang Province, $Y$ was made to represent the decision result of farmers' choice of fertilizer application. According to the benefit effect of different chemical fertilizer application decisions, this paper will reduce chemical fertilizer application, keep chemical fertilizer application unchanged, and increase chemical fertilizer use from low to high. Because the dependent variable is an ordered classification variable, this paper uses the ordered Probit model for empirical estimation. The general form of the model can be expressed as follows:

$$
Y=\beta_{0}+\beta_{1} R F+\beta_{2} R C+\beta_{3} X+\varepsilon
$$

In the model, the explained variable $Y$ is the latent variable, and $\beta_{0}, \beta_{1}, \beta_{2}$, and $\beta_{3}$ are estimated coefficients. $\varepsilon$ is the residual term, subject to normal distribution, and the variance is $\sigma^{2}$, that is, $\mathcal{E} \sim N\left(0, \sigma^{2}\right) . R F$ and $R C$ are the core explanatory variables, $R F$ is the risk preference index, and $R C$ is the risk perception. $X$ is the vector of control variables, including grain farmers families' characteristics, policy promotion, and other variables.

\section{Data Sources and Descriptive Statistics}

3.1. Data Sources. The data used in this paper is from a multistage stratified sampling survey of grain farmers in Heilongjiang Province in November 2018. First of all, because Heilongjiang Province is the main grain producing area in China, the main research object is to select grain growers. Secondly, according to the level of economic development and geographical distribution stratified sampling, 3 sample counties were selected. Two sample townships were selected from each district in the same way. Finally, considering the production behavior of grain farmers with different scale of operation may be different, in each sample county, random scale households and nonscale households. The survey interviewed 152 grain farmers and collected 137 valid questionnaires. Table 1 displays the definition of each variable and the descriptive statistical results of 137 grain farmers surveyed.

\subsection{Descriptive Statistical Analysis of Variables}

3.2.1. Fertilization Behavior. The explained variable in this paper is the change behavior of chemical fertilizer application rate of grain farmers in Heilongjiang Province, which is an orderly classified variable, reduces the assignment value of chemical fertilizer application rate to 0 , keeps the constant assignment value of chemical fertilizer application rate to 1 , and increases the assignment amount of chemical fertilizer application rate to 2 . The statistical results are shown in Figure 1, 16.79\% of the grain farmers chose to reduce the amount of chemical fertilizer, $48.18 \%$ of the farmers chose to keep the amount of chemical fertilizer unchanged, and $35.03 \%$ of the farmers chose to increase the amount of chemical fertilizer. Thus, it can be seen that most grain farmers in Heilongjiang Province basically keep the level of chemical fertilizer application unchanged.

3.2.2. Risk Preference. The risk preference of grain farmers is obtained by using the method of risk preference measure, as shown in Table 2. Use the investment preference to measure the risk preference. Raise questions about the investigated grain farmers: if you have one thousand yuan to invest, you will receive five possible returns, which one do you prefer? According to the different answers of grain farmers, the risk preference is positioned. The results are as follows: if the farmers choose the option of 1000 yuan, they are very risk averse. If farmers choose the option of grain may be 900 yuan or 1600 yuan, the probability of the two benefits is the same; it is more risk averse. If the income of grain farmers may be 800 yuan or 2000 yuan, the probability of the two kinds of income is the same; it is a general risk type. If the grain farmers choose the option to gain 400 yuan or 3000 yuan, the probability of obtaining the two kinds of income is the same; it is the risk type. If the income of grain farmers may be 0 yuan or 4000 yuan, the two kinds of income gain the same probability; it is a very preference for risk. The results show that the average risk preference of grain farmers in Heilongjiang Province is 2.31, the standard deviation is 1.14 , and the overall risk type is close, showing the type of risk avoidance.

3.2.3. Risk Perception. This paper explores the influencing factors of fertilization behavior decision-making in agricultural production of grain farmers and therefore does not consider factors such as social risks that farmers may face. Choose only consider the agricultural natural risks that may occur in the production process as the research point of this paper risk perception factors, the survey results are shown in Table 3. The risk perception of grain farmers is measured by the following question: "Do you expect the environment for agricultural production to deteriorate in the future?" When farmers expect "the future agricultural production environment will become worse," it means that farmers perceive the existence of agricultural natural risk. On the contrary, it means that farmers do not perceive agricultural natural risk. The results show that $40.88 \%$ of the 137 grain farmers think that the agricultural production environment will become 
TABLE 1: Name, meaning, and statistical characteristics of variables.

\begin{tabular}{|c|c|c|c|c|c|}
\hline $\begin{array}{l}\text { Variable } \\
\text { Name }\end{array}$ & Variable meaning and assignment & Mean & $\begin{array}{l}\text { Standard } \\
\text { deviation }\end{array}$ & Minimum & Maximum \\
\hline Behavior & $\begin{array}{c}\text { Fertilizer application behavior of farmers } \\
\text { Reduce the amount of fertilizer application }=0 \\
\text { The amount of chemical fertilizer application remained unchanged }=1 \text {. } \\
\text { Increase the amount of chemical fertilizer }=2 . \\
\text { Risk preference }\end{array}$ & 1.18 & 0.70 & 0 & 2 \\
\hline $\mathrm{RF}$ & $\begin{array}{l}\text { Very averse to risk }=1 \text {, more risk averse }=2 \text {, general preference risk }=3 \text {, } \\
\text { comparative preference for risk }=4 \text {, and very risk averse }=5 \\
\text { Risk perception }\end{array}$ & 2.31 & 1.14 & 1 & 5 \\
\hline $\mathrm{RC}$ & $\begin{array}{l}\text { Do you feel that the future agricultural production environment will } \\
\text { become worse? } \\
\text { No }=0 \text {, yes }=1\end{array}$ & 0.41 & 0.49 & 0 & 1 \\
\hline Age & $\begin{array}{c}\text { Age of head of household } \\
\text { Unit: years old }\end{array}$ & 41.55 & 7.34 & 26 & 61 \\
\hline $\begin{array}{l}\text { Education } \\
\text { level }\end{array}$ & $\begin{array}{l}\text { Primary school and below }=1, \text { middle school }=2 \text {, high school or technical } \\
\text { secondary school }=3 \text {, and college or above }=4\end{array}$ & 2.23 & 0.60 & 1 & 4 \\
\hline Time & $\begin{array}{l}\text { Engaged in agricultural planting time } \\
\text { Unit: years }\end{array}$ & 16.42 & 8.52 & 2 & 40 \\
\hline Number & $\begin{array}{c}\text { The number of households participating in agricultural production } \\
\text { Unit: person }\end{array}$ & 2.12 & 0.88 & 1 & 8 \\
\hline Area & Families own arable land; unit: $\mathrm{Mu}$ & 194.24 & 204.05 & 20 & 1385 \\
\hline Income & Annual family income; unit: 10000 yuan & 17.12 & 17.16 & 2 & 98 \\
\hline Train & $\begin{array}{l}\text { Have you received chemical fertilizer training? } \mathrm{No}=0 \text {, yes }=1 \\
\text { The effect of chemical fertilizer on agricultural ecological environment }\end{array}$ & 0.37 & 0.48 & 0 & 1 \\
\hline Cognition & $\begin{aligned} \text { No effect }=0 \text {, slight effect } & =1 \text {, general effect }=2 \text {, large impact }=3 \text {, and } \\
& \text { severe impact }=4\end{aligned}$ & 1.99 & 1.13 & 0 & 4 \\
\hline Policy & $\begin{array}{l}\text { Are you willing to reduce fertilization if the government provides fertilizer } \\
\text { subsidies? } \\
\text { No }=0 \text {, yes }=1\end{array}$ & 0.55 & 0.50 & 0 & 1 \\
\hline
\end{tabular}

$\mathrm{Mu}$ is the unit of land measurement in China, equivalent to about 666.67 square meters.

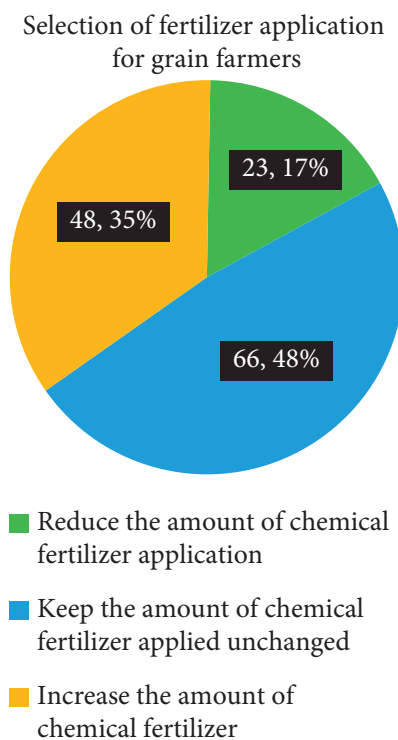

FIGURE 1: Selection of fertilizer application behavior of grain farmers.

worse in the future, and $59.12 \%$ of the grain farmers expect the agricultural production environment to not deteriorate in the future; that is to say, more than half of the farmers are optimistic about the possible agricultural natural risks in the future.
3.2.4. Other Control Variables. In this paper, the main control variables are the householder characteristics, production and management characteristics, and subsidy policies of the investigated grain farmers.

The main characteristics of heads of grain farmers include the age of heads of households, education, experience of heads of households, whether heads of households have received fertilizer-related technical training, and heads of household fertilizer pollution awareness as control variables. According to the statistics of the survey results, the average age of the farmers surveyed is 42 years, the average education level is junior high school level, and the average number of years of agricultural planting of the head of household is 16.42 years. It can be seen that farmers have rich planting experience. $37 \%$ of the grain farmers have received training in fertilizer-related technologies; the results are shown in Figure 2. The surveyed grain farmers generally believed that the environmental impact of chemical fertilizer pollution was general.

The production and management characteristics of grain farmers mainly include investigating the number of farmers engaged in agricultural production, planting scale, and family annual income level. The average number of farmers engaged in agricultural production is 2 , the average family planting scale is $194 \mathrm{mu}$, and the largest planting scale is about $1385 \mathrm{mu}$. The average income of the sample family farming was 170,000 yuan. 
TABLE 2: Risk preference measures.

\begin{tabular}{|c|c|c|c|}
\hline Question & Answer options & $\begin{array}{l}\text { Types of risk } \\
\text { preference }\end{array}$ & Frequency \\
\hline \multirow{5}{*}{$\begin{array}{l}\text { If you have } 1000 \text { yuan to invest, you will receive five possible returns. } \\
\text { Which one do you prefer? }\end{array}$} & Income 1000 yuan & Very risk averse & 41 \\
\hline & $\begin{array}{l}\text { The income may be } 900 \text { yuan or } \\
1600 \text { yuan }\end{array}$ & More risk averse & 40 \\
\hline & $\begin{array}{l}\text { The income may be } 800 \text { yuan or } \\
2000 \text { yuan }\end{array}$ & General risk type & 35 \\
\hline & $\begin{array}{l}\text { The income may be } 400 \text { yuan or } \\
3000 \text { yuan }\end{array}$ & Risk preference & 15 \\
\hline & $\begin{array}{l}\text { The income may be } 0 \text { yuan or } \\
4000 \text { yuan }\end{array}$ & Very risk oriented & 6 \\
\hline
\end{tabular}

TABLE 3: Risk perception measures.

\begin{tabular}{lcc}
\hline Question & Answer options & Frequency \\
\hline \multirow{2}{*}{ Do you expect the agricultural production environment to become worse in the future? } & Yes & 56 \\
& No & 81 \\
\hline
\end{tabular}

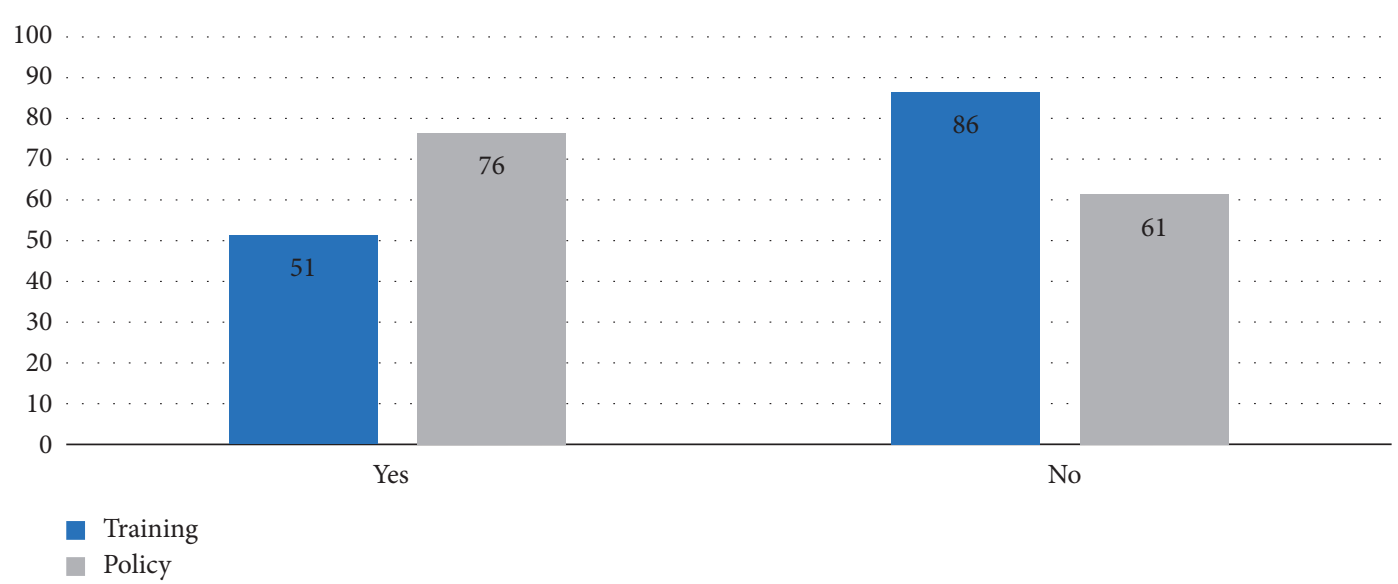

FIgURE 2: Situation of farmers receiving fertilization technology training and policy incentive selection.

In order to investigate the change of fertilization decision of grain farmers under the condition of government subsidies, the question was raised: "Does the government choose to reduce fertilizer application?" According to the results of the survey, 55\% of farmers are willing to reduce the amount of fertilizer application under the condition that the government provides fertilizer subsidies; the results are shown in Figure 2.

\section{Analysis of Empirical Results}

According to the output of Stata 15 software, the Probit regression analysis of survey data was carried out. The running results of the model are shown in Table 4 . The fitting degree of the pseudo- $R^{2}$ interpretation model is closer to 1 , which means that the fitting degree of the model is better. From the results of model estimation, the value of pseudo- $R^{2}$ is 0.7315 , which is at a high level. Therefore, the model fitted well, and most of the variables have an impact on farmer's decision-making of fertilization behavior.
4.1. Impact of Risk Preference. According to the results of the effect of risk preference in Table 2 on the fertilization behavior of grain farmers in Heilongjiang Province, this factor was significant at the significance level of $1 \%$ and was negative, with a coefficient of 1.88; that is, grain farmers with high risk preference tend to choose to reduce fertilizer application behavior decision. Chemical fertilizer is an important agricultural product to ensure the yield of modern agriculture. Proper application of chemical fertilizer can effectively reduce the possibility of crop yield reduction and increase loss. According to previous relevant studies, risk preference has a significant impact on farmers' fertilizer behavior, and some of the results show that farmers with low risk preference are more inclined to choose to increase fertilizer application in order to avoid the natural risk of agriculture. This study also verifies the validity of this conclusion.

4.2. Impact of Risk Perception. The effect of risk perception on fertilizer application behavior of grain farmers in Heilongjiang Province was analyzed in Table 2. The results 
TABle 4: Model estimation results.

\begin{tabular}{|c|c|c|c|c|c|c|}
\hline Variable name & Coef. & Std. Err. & $z$ & $P>|z|$ & \multicolumn{2}{|c|}{ 95\% Conf. interval } \\
\hline $\mathrm{RF}$ & $-1.880^{* * *}$ & 0.578 & -3.25 & 0.001 & -3.014 & -0.746 \\
\hline $\mathrm{RC}$ & $1.573^{*}$ & 0.835 & 1.88 & 0.060 & -0.065 & 3.210 \\
\hline Age & -0.027 & 0.064 & -0.42 & 0.673 & -0.151 & 0.098 \\
\hline Education level & 0.546 & 0.642 & 0.85 & 0.395 & -0.712 & 1.804 \\
\hline Time & -0.123 & 0.076 & -1.61 & 0.108 & -0.272 & 0.027 \\
\hline Number & 0.234 & 0.405 & 0.58 & 0.563 & -0.560 & 1.028 \\
\hline Area & $0.017^{* *}$ & 0.007 & 2.44 & 0.015 & 0.003 & 0.031 \\
\hline Income & $-0.167^{* *}$ & 0.071 & -2.35 & 0.019 & -0.306 & -0.028 \\
\hline Train & $-2.043^{* * *}$ & 0.786 & -2.60 & 0.009 & -3.583 & -0.503 \\
\hline Cognition & $-1.136^{* *}$ & 0.480 & -2.37 & 0.018 & -2.078 & -0.195 \\
\hline Policy & -0.906 & 0.748 & -1.21 & 0.226 & -2.373 & 0.560 \\
\hline _Cons & 12.714 & 4.364 & 2.91 & 0.004 & 4.160 & 21.268 \\
\hline Log likelihood $=-16.642974$ & \multicolumn{6}{|c|}{$\begin{array}{l}\text { Number of obs }=137 \\
\text { LR chi } 2(11)=90.70 \\
\text { Prob }>\text { chi } 2=0.0000 \\
\text { Pseudo }-R^{2}=0.7315\end{array}$} \\
\hline
\end{tabular}

${ }^{* * *},{ }^{* *},{ }^{*}$, respectively, represent $1 \%, 5 \%$, and $10 \%$ of the statistics of the level.

showed that the factor was significant at $10 \%$ significance level and had a positive effect with a coefficient of 1.573; that is to say, grain farmers with high risk perception tended to choose to increase chemical fertilizer application behavior decision. Thus, it can be seen that the natural risk has a great influence on the fertilizer behavior of grain farmers. In the absence of effective natural risk aversion methods, grain farmers will usually choose to use a certain amount of chemical fertilizer to avoid the risk after perceiving the natural risk, but the result of this kind of behavior decision often leads to excessive fertilizer.

4.3. Impact of Other Variables. Observing the results of other control variables in Table 2, we can see that the training factor of fertilization technology is significant at the significance level of $1 \%$, and the influence direction is negative, which indicates that farmers who have been trained in fertilization technology are more inclined to choose the decision of reducing fertilizer application behavior. After fertilization technology training of grain farmers, they may choose more reasonable fertilization behavior to ensure their own production income, rather than relying on fertilizer to ensure grain yield. Cultivated area, total income of family agriculture, and knowledge of environmental impact of fertilization were significant at the significant level of $5 \%$. The influence direction of cultivated land area was positive, which indicated that grain farmers with larger cultivated land were inclined to increase fertilizer application. The influence direction of total agricultural production income and fertilization on environmental impact cognition was negative, indicating that grain farmers with high household income tended to choose to reduce fertilizer application behavior. Grain farmers themselves believe that the severity of fertilization on the environment impels grain farmers to make the opposite fertilization behavior; that is to say, the more serious the impact of chemical fertilizer on environment, the more grain farmers are willing to choose to reduce fertilizer application behavior decision. In the model, the age of the householder, the length of time the householder engaged in farming, and the subsidy policy had a negative effect on the fertilization behavior of the grain farmer. The education level of the head of household and the number of farmers have positive effects on the fertilization behavior of grain farmers, but the results are not significant.

\section{Conclusions and Suggestions}

In this paper, a questionnaire survey was conducted among grain farmers in Heilongjiang Province. The Probit empirical model was used to analyze the influence mechanism of risk preference and risk perception on fertilizer application behavior decision of grain farmers. The results showed that the high risk preference of grain farmers had a negative effect on the decision-making behavior of chemical fertilizer application, and the high degree of natural risk perception had a positive effect on the chemical fertilizer application behavior of grain farmers. At the same time, the results showed that the cultivated land area owned by farmers, the total income of agricultural production, the training of fertilizer technology, and the cognition of the impact of fertilizer on the environment all had significant effects on the chemical fertilizer application behavior of grain farmers.

With the increasing diversification and high standardization of food demand by Chinese consumers, food quality, food safety, environmental protection, and other aspects of demand, agrochemical residues have been widely concerned. The high use and low efficiency of agricultural chemical fertilizer in China have brought a series of environmental problems, which has become an important factor of hindering the sustainable development of agriculture and threatening the quality and safety of agricultural products. Therefore, the above conclusions have certain policy significance. First, the characteristics of strong risk aversion and relying on natural risk perception to predict fertilization behavior were used to guide grain farmers to learn and use 
new technologies such as conservation tillage. The sustainable development of agriculture can be promoted by improving the ability of grain farmers to resist agricultural natural risks through advanced farming techniques. Secondly, because grain farmers as a whole have received low level of training in fertilizer technology, by increasing the training of fertilizer application technology to grain farmers, the knowledge of scientific fertilizer application is improved, and through the scientific proportion of more effective selection of chemical fertilizer application amount, excessive fertilizer application phenomenon is avoided. Third, the relevant departments should strengthen the popularization of science and publicity on the impact of chemical fertilizer application on the living environment, production environment, and food safety and enhance the awareness of the impact of chemical fertilizer application on grain farmers which can effectively improve the chemical fertilizer application choice of grain farmers and achieve the purpose of grain farmers choosing to reduce chemical fertilizer application behavior.

\section{Data Availability}

The data that support the findings of this study are available from the corresponding author upon reasonable request.

\section{Conflicts of Interest}

The authors declare no conflicts of interest.

\section{Authors' Contributions}

All authors have seen the manuscript and approved to submit it.

\section{Acknowledgments}

This work was financially supported by the National Natural Science Foundation Project on "Farmers' Behavior of Fertilizer Application and Agricultural Non-Point Source Pollution Control: Impact Mechanism and Policy Simulation Research" (71573036), National Social Science Foundation: Research on the Coupling of Blockchain Technology and Supply Chain Governance of Agricultural Ecological Products (20FGLB059), Study on the Behavior Response and Incentive Mechanism of Farmers' Low Carbon Agricultural Technology Adoption in Heilongjiang Province (2572019BM01), and Research on Performance Evaluation and Mechanism Construction of Circular Agriculture Development of Agricultural Enterprises in Heilongjiang Province (18GLD301).

\section{References}

[1] M. Li, C. Zhou, and L. Lian, "Risk assessment of agricultural flood and drought disasters in China based on entropy information diffusion theory," Journal of Natural Resources, vol. 32, no. 4, pp. 620-631, 2017.

[2] S. Ma and H. Ye, "Research on China's food security based on the effective supply of cultivated land resources at home and abroad," Agricultural Economic Issues, vol. 36, no. 6, pp. 9-19, 2015.
[3] J. Wang, W. Ma, R. Jiang et al., "Integrated management of nutrient resources and food security in China," Resource Science, no. 3, pp. 415-422, 2008.

[4] X. Xie and J. Zhu, "Analysis of regional differences in influencing factors of cultivated land quality and Research on improvement approaches-taking Xinzheng City, Henan Province as an example," China Land Science, vol. 31, no. 6, pp. 70-78, 2017.

[5] K. Li and D. Ma, "Research on Farmers' behavior and decision-making mechanism of fertilizer reduction in ecologically vulnerable areas: a case study of 421 farmers in 4 counties of Shanxi Province," Journal of Nanjing Agricultural University (Social Science Edition), no. 5, pp. 138-145, 2018.

[6] C. Chao, Y. Wang, and Q. Zhai, "Risk preference, risk perception and pesticide application behavior of peach farmers," Journal of Jiangxi Agricultural University (Social Science Edition), vol. 18, no. 4, pp. 472-480, 2019.

[7] X. Cheng, X. Jia, J. Huang et al., "Effects of agricultural technology training on farmers' nitrogen application behavior: an empirical study based on maize production in shouguang city, shandong province," Agricultural Technology Economy, no. 9, pp. 4-10, 2012.

[8] Q. Gong, X. Mu, and Z. Tian, “Analysis on Influencing Factors of farmers' risk perception and avoidance ability of excessive fertilization-based on a questionnaire survey of 284 farmers in Jianghan Plain," China Rural Economy, no. 10, pp. 66-76, 2010.

[9] J. Ma and X. Cai, “Analysis of farmers' willingness to reduce nitrogen application rate and its influencing factors-taking North China Plain as an example," China Rural Economy, no. 9, pp. 9-16, 2007.

[10] Y. Jiang, R. Lei, X. Guo et al., "Spatial variability of soil nitrogen and its influencing factors in Jiangxi Province," Resources and Environment of the Yangtze River Basin, 2018.

[11] J. W. Pratt, "Risk aversion in the small and in the large," Econometrica, vol. 32, no. 1/2, pp. 122-136, 1964.

[12] J. A. Roumasset, Rice and Risk: Decision-Making Among LowIncome Farmers, North-Holland Press, no. 98, Amsterdam, Netherlands, 1976.

[13] J. C. Scott, The Moral Economy of the Peasant: Rebellion and Subsistence in Southeast Asia, Yale University Press, London, UK, 1977.

[14] Z. He, L. Hu, and Q. Lu, “Influence of farmers' risk preference and risk cognition on willingness to adopt water-saving irrigation technology," Resource Science, vol. 40, no. 4, pp. 797-808, 2018.

[15] Q. Huanguang, H. Luan, L. Jin et al., "Impact of risk aversion on Farmers' excessive fertilizer application behavior," China Rural Economy, no. 3, pp. 85-96, 2014.

[16] J. L. Lusk and K. H. Coble, "Risk perceptions, risk preference, and acceptance of risky food," American Journal of Agricultural Economics, vol. 87, no. 2, p. 393, 2005.

[17] V. Patil and P. C. Veettil, "Experimental evidence of risk attitude of farmers from risk-preference elicitation in India," International Association of Agricultural Economists, 2018.

[18] E. Camacho-Cuena and T. Requate, "The regulation of non-point source pollution and risk preferences: an experimental approach," Ecological Economics, vol. 73, no. 1727, pp. 179-187, 2012.

[19] H. Qiu, L. Su, Y. Zhang et al., "Risk preference, risk perception and farmers' adoption of conservation tillage technology," China Rural Economy, no. 7, pp. 59-79, 2020. 
[20] Y. Li, J. Fu, P. Li et al., "A review of experimental research on risk preference," Science and Technology and Management, no. 5, pp. 34-37, 2009.

[21] C. A. Holt and S. K. Laury, "Risk aversion and incentive effects," American Economic Review, vol. 92, no. 5, pp. 1644-1655, 2002. 